\title{
Effect of high-intensity interval training on treadmill exercise with changes in inclination on Heart Rate Variability in overweight/obese men
}

\author{
I Komang Gede Dwi Maya Rustadi ${ }^{1}$, Damayanti Tinduh ${ }^{2 *}$, Ditaruni Asrina Utami ${ }^{3}$ \\ ${ }^{1}$ Physical Medicine and Rehabilitation Resident, Faculty of Medicine, Airlangga University, Surabaya, Indonesia \\ ${ }^{2}$ Department of Physical Medicine and Rehabilitation, Faculty of Medicine, Airlangga University, Surabaya, Indonesia \\ Corresponding author: damayanti.tinduh@fk.unair.ac.id;
}

\begin{abstract}
Overweight and obesity have been associated with cardiovascular disease, diabetes mellitus type 2, osteoarthritis, respiratory disorders, cancer, and decline in life expectancy. Cardiac autonomic modulation can be assessed based on Heart Rate Variability (HRV), which is an important marker of cardiovascular risk. High Intensity Interval Training (HIIT) have been developed as an alternative exercise with low volume and expected to help efficiently reduce risk factors associated with the overweight condition. To evaluate the effect of the HIIT exercise program for 4 weeks on HRV in overweight men in Medical Rehabilitation Outpatient Clinic at dr. Soetomo Hospital. This study was conducted from October to December 2020. Eighteen men visited Medical Rehabilitation Outpatient Clinic at dr. Soetomo Hospital were recruited and randomized into the control and exercise groups. The exercise group performed the HIIT exercise program for 4 weeks and the control group received no intervention. HRV measurement was done before and after the intervention for the exercise group and for the control group was taken before and after 4 weeks of observation. Within-group comparison in exercise group showed significant increase in RMSSD and SDNN while decrease LF/HF ratio $(p=0.009, p=0.017$, and $p=0.034$, respectively). Withingroup comparison in control group showed no significant differences. Between-group comparison at the end of study showed no significant differences. The HIIT exercise program for 4 weeks showed significant increase in RMSSD and SDNN also decrease the LF/HF ratio in overweight/obese men.
\end{abstract}

Keywords: high intensity interval training (HIIT); Overweight; Obesity; HRV; SDNN; RMSSD; LF/HF ratio

\section{Introduction}

Overweight and obesity have been identified as major health problems worldwide (Speiser et al., 2005). It is associated with an increased risk of cardiovascular disease, type 2 diabetes mellitus, osteoarthritis, respiratory problems, and cancer as well as decreased life expectancy (Ouerghi et al., 2017). Therefore, obesity and obesityrelated comorbidities are a major challenge to health systems and present as an important public health problem worldwide. WHO developed the Global Action Plan for the Prevention and Control of Non-communicable Diseases 2013-2020. One of the 9 targets of global non-communicable diseases is to overcome the prevalence of obesity. Diabetes and obesity prevalence must be controlled by 2025 from 2010 (World Health Organization, 2013). Obesity rates continue to increase in both developed and developing countries (Heydari et al., 2012; Speiser et al., 2005). Based on the 2018 Basic Health Research (Riskesdas) data, the epidemiology of overweight (an indicator of overweight in adults, namely BMI 25.0 to <27) at the age of 18 years is around $13.6 \% 21.8 \%$. While the obesity rate in adults is around $21.8 \%$ (an indicator of obesity in adults is BMI 27,0). This figure is expected to continue to increase. Since being overweight is associated with various health problems, an effective fat loss strategy is needed (Heydari et al., 2012). Interactive educational interventions and patient-centered care are effective in improving metabolic control, independent nursing behavior, and quality of life. The American College of Sports Medicine (ACSM) recommends moderate to vigorous-intensity aerobic exercise at least 150 minutes a week (30 minutes, 5 times a week) accompanied by 2-3 weight training sessions a week. Despite the benefits of doing such exercise, many people find it difficult to achieve the volume target of the exercise. To overcome this, high-intensity interval training (HIIT) has been developed as a form of low-volume exercise and is expected to be an efficient way to reduce the risk caused by being overweight. Several studies have linked the effect of highintensity interval training on cardiovascular health, metabolic capacity, and aerobic performance that has the same effect and are even superior when compared to moderate-intensity aerobic exercise (Kilpatrick, et al, 2014).

The autonomic nervous system has an important role in the regulation of the cardiovascular system. Cardiac autonomic modulation can be assessed based on heart rate variability (HRV), which is the variation between adjacent heart rates. HRV is an important marker of cardiovascular risk which provides an overview of early changes in the autonomic control of the heart. Low HRV values indicate decreased in cardiac parasympathetic activity and have been associated with cardiovascular disease, diabetes, sleep disturbances, and 
emotional disturbances (Farah et al., 2014). Based on the description above, the researchers estimated that giving high-intensity interval training to overweight/obese patients could reduce cardiovascular risk by assessing HRV changes. Therefore, the researchers wanted to evaluate the benefits of high-intensity interval training on changes in HRV in overweight/obese patients.

\section{Materials and Methods}

This study is an experimental study with pre and posttest randomized control group design. The purpose of this study is to observe the effect of 4 weeks HIIT intervention to the Heart Rate Variability in male overweight/obese participant between age 18-55 years old at Medical Rehabilitation outpatient clinic dr. Soetomo Hospital. Subject allocated into exercise group (9 subjects) and control group (9 subjects). Exercise group perform 4 weeks of HIIT exercise session using treadmill walking, each session lasted \pm 42 minutes, 3 times a week. Control group continue doing activities as usual.

\section{Participants}

Overweight/obese patients aged 18-55 years who visited the Medical Rehabilitation Polyclinic of RSUD Dr. Soetomo Surabaya who met the inclusion criteria and was excluded in the exclusion criteria were given information about the aims and objectives of the study. Participants were asked to sign the informed consent form after receiving an explanation. Research subjects were taken by consecutive sampling. Inclusion criteria included: Male with Body Mass Index (BMI) $>23 \mathrm{~kg} / \mathrm{m} 2$; Age 18-55 years; Normal cognitive function; Systolic blood pressure $<140 \mathrm{mmHg}$, diastolic $<90 \mathrm{mmHg}$. Exclusion criteria: erythema, sores, ulcers, or gangrene in one or both feet, peripheral neuropathy, the range of motion of both ankles for plantar flexion $<45$ degrees and dorsiflexion < 20 degrees, Is routinely perform aerobic exercise, diagnosed with ischemic heart disease, restrictive or obstructive airway disease, neuromusculoskeletal vascular disease of the lower limbs that interferes with ambulation function, impaired vision, impaired balance, recent stroke or transient ischemic attack, fever, renal failure, history of coronary artery bypass surgery $(<4$ weeks) or percutaneous intervention $(<3$ weeks $)$. Eligible participants were included and randomized into exercise group $(\mathrm{n}=9)$ and control group $(\mathrm{n}=9)$.

\section{Anthropometric parameters}

The body weight of the participants was measured on a scale with $0.1 \mathrm{~kg}$ readability. The participants didn't use any footwear, and wore light clothes. The height of participants was measured using a stadiometer with $0.1 \mathrm{~cm}$ readability. The body mass index is defined as the ratio of the mass of body in kilograms, divided by body height in meters squared. The overweight was $23-24.9 \mathrm{~kg} / \mathrm{m}^{2}$, and obese was above $25.0 \mathrm{~kg} / \mathrm{m}^{2}$.

\section{HRV measurements}

HRV recording was performed in the morning before the activity. During recording, the participants were in a sitting position and asked to remain calm during recording. The recording is done using a Polar $\mathrm{H} 10$ connected to a Samsung Galaxy Note 4 smartphone via Bluetooth using the Elite HRV application. The recording is done for 5 minutes. The recording data is then transferred to a computer for later analysis using Kubios HRV Standard 3.3 software. The data taken are RMSSD, SDNN, and LF/HF ratio. The exercise group was recorded before the intervention and 2 days after the last exercise while the control group was recorded before and after the 4 -week observation period.

\section{Intervention}

The exercise group received HIIT exercises using a BTL treadmill connected to an electrocardiogram monitor. The workout begins with a 5 -minute warm-up by walking at $2 \mathrm{mph}$ at a $0 \%$ inclination. The exercise was then continued with high-intensity exercise for 2 minutes and low-intensity exercise for 2 minutes with a total duration of 32 minutes of core training. Determination of exercise intensity by adjusting the inclination height of the treadmill at the same speed of $2 \mathrm{mph}$. The high intensity was calculated using the Karvonen formula with high intensity defined as HR rest + 80-90\% HR Reserve and low intensity defined as HR Rest + 30-40\% HR Reserve. After the core workout, cool down at a speed of $2 \mathrm{mph}$ and an inclination of $0 \%$. Exercises are carried out 3 times a week for 4 weeks with a total of 12 training sessions, the distance between exercises is not more than 2 days. The control group was educated to carry out daily activities as usual.

\section{Statistical Analysis}

The values are reported as mean \pm standard deviations. Statistical analyses were carried out by IBM SPSS (Statistical Package for Social Sciences (SPSS), Version 23, Chicago, IL). All data were normally distributed checked by Shapiro-Wilk test. The dependent paired t-test was utilized to determine the within group changes from pre- to post-test and independent t-test was conducted to investigate the changes between two groups concerning post-test values. 


\section{Results and Discussion}

All participants successfully fulfill the intervention, no side effects were reported. Comparison of characteristics between the two study groups was compared based on age, height, weight, and BMI. From BMI data, 33\% of the control group were in the overweight category and 66\% were in the obesity category, from the treatment group $22 \%$ were in the overweight category and $77 \%$ were in the obese category. All study subjects had no comorbidities that would affect HRV recording (ischemic heart disease, heart rhythm disturbances, restrictive or obstructive airway disease). Other factors that affect HRV measurements such as psychological factors (depression, stress), use of pacemakers, use of beta-blocker drugs, or other antiarrhythmic drugs were excluded from the study subjects so that they would not affect HRV values at the time of recording.

Table 1 The Demographic and Anthropometric Data.

\begin{tabular}{|l|c|c|c|}
\hline Variable & Exercise group $(\mathrm{n}=9)$ & Control group $(\mathrm{n}=9)$ & $\mathrm{p}$ value \\
\hline Age $($ Years $)$ & $30.4 \pm 2.6$ & $36 \pm 1.8$ & 0.407 \\
\hline Height $(\mathrm{cm})$ & $168.3 \pm 5.8$ & $167.11 \pm 6.97$ & 0.794 \\
\hline Weight $(\mathrm{kg})$ & $79.5 \pm 10.3$ & $76.2 \pm 11.57$ & 0.482 \\
\hline BMI $\left(\mathrm{kg} / \mathrm{m}^{2}\right)$ & $28 \pm 2.7$ & $27.15 \pm 2.83$ & 0.657 \\
\hline
\end{tabular}

Values are presented as mean \pm SD. BMI: body mass index

This study reveals significant changes in RMSSD $(p=0,009)$, SDNN $(p=0,017)$ and LF/HF ratio $(p=$ 0.034 ) at the exercise group with large effect size for RMSSD, SDNN, and LF/HF ratio (Cohen's D 1.0; 1.15; 0.85 respectively), no significant changes in RMSSD, SDNN and LF/HF ratio at the control group over 4 weeks of observation. There was no significant difference at the RMSSD $(p=0.059)$, SDNN $(p=0.203)$, and LF/HF ratio $(p=0.120)$ between groups at the end of observation.

Table 2 Changes in Heart Rate Variability Parameters

\begin{tabular}{|l|c|c|c|c|}
\hline \multirow{2}{*}{ Parameter } & \multicolumn{2}{|c|}{ Exercise Group } & \multicolumn{2}{c|}{ Control Group } \\
\cline { 2 - 5 } & Pre & Post & Pre & Post \\
\hline SDNN & $33.34 \pm 16.98$ & $49.64 \pm 30.47^{*}$ & $38.93 \pm 13.70$ & $34.11 \pm 5.52$ \\
\hline RMSSD & $28.08 \pm 17.06$ & $51.88 \pm 25.62^{*}$ & $37.58 \pm 17.68$ & $34.94 \pm 13.23$ \\
\hline LF/HF Ratio & $1.76 \pm 1.11$ & $1.48 \pm 0.80^{*}$ & $1.76 \pm 1.11$ & $2.30 \pm 1.26$ \\
\hline
\end{tabular}

Values are presented as mean \pm SD. *Significantly different from baseline $(\mathrm{P}<0.05)$.SDNN: standard deviation of normal to normal R-R intervals, RMSSD: root mean square of the successive differences, LF/HF ratio high frequency / low frequency.

A systematic review study by Picard et al., (2021) who studied the effect of physical exercise on HRV in patients with type 2 diabetes mellitus found that after physical exercise there was an increase in SDNN and RMSSD. After stratification by exercise type, HIIT showed improvements in RMSSD and LF/HF ratio. The study by Ahmed et al., (2019) that studied the effect of 12 weeks of HIIT on HRV in overweight and obese subjects with type 2 diabetes mellitus also found an increase in $\operatorname{RMSSD}(23 \% ; \mathrm{p}<0.05)$ and $\operatorname{SDNN}(28 \% ; \mathrm{p}<0.05)$ and a decrease in the value of the LF/HF ratio by $31 \%$ in the treatment group. Researchers suggest that the improvement in HRV values after 4 weeks of HIIT exercise is the effect of repeated pressure on blood vessels and changes in baroreceptors after HIIT exercise. The mechanism of HIIT provides an improvement in HRV values as illustrated by an increase in the value of SDNN, RMSSD, and a decrease in the LF/HF ratio, presumably through repeated pressure on the blood vessel walls that stimulates the endothelium to synthesize nitric oxide (NO). In addition, HIIT increases the expansion of the carotid arteries which will increase baroreceptor sensitivity (Heydari, et al., 2013). RMSSD is associated with HF power which indicates the parasympathetic activity of the heart. LF power shows the index of sympathetic and parasympathetic with predominantly sympathetic and LF/HF ratio shows sympathovagal balance (Picard, et al., 2020). In this study, there was a decrease in the LF/HF ratio in the treatment group which indicated an increase in the dominance of the parasympathetic over the sympathetic. This is in line with the increase in the RMSSD value which also indicates an increase in the parasympathetic activity of the heart. Researchers suggest that there is an increase in cardiac parasympathetic activity after 4 weeks of HIIT exercise in the treatment group.

Vasconcellos et al., (2016) which examined the effect of a 12-week recreational soccer program on adolescents aged 12-17 years with obesity found that there was an increase in parasympathetic dominance in the treatment group by observing HRV values, but between there was no significant difference between the treatment and control groups.

The results of this study are different from research by Ahmed, et al., (2019) which found that there were significant differences in the values of the RMSSD, SDNN, and LF/HF ratio between the HIIT exercise group and the control group after a 12-week observation period. A study by Ahmed, et al., (2019) used an interval period 
of 4 minutes of high-intensity exercise and 2 minutes of low-intensity exercise for 30 minutes 3 times a week in subjects with obesity and suffering from type 2 diabetes mellitus. required to fast for 12 hours before recording. The subjects in the study by Ahmed, et al., (2019) were obese men with comorbid diabetes mellitus, different from this study which only used overweight/obese subjects without diabetes mellitus. The interval volume in the study by Ahmed et al., (2019) was also different, which used a 4-minute high and a 2-minute low interval. The duration of the exercise intervention is also different whereas Ahmed et al., (2019) observed for 12 weeks, while in this study it was only 4 weeks. The researcher argues that differences in subject characteristics, differences in the composition of exercise intervals, and different durations of observation can be factors that influence the differences in the results of this study compared to research by Ahmed, et al., (2019). According to Rodrigues et al., (2019) fasting 12 hours before recording HRV did not have a different effect on not fasting before recording HRV. So that the factor of recording HRV 12 hours after fasting in the study by Ahmed, et al., (2019) was not associated with differences in HRV recording results in this study. In addition, in this study, the RMSSD, SDNN, and LF/HF ratio values in the treatment and control group subjects were still in normal values both before and after 4 weeks of observation. This could be a factor that caused the improvement in HRV values in the treatment group not significantly different from the control group after 4 weeks of observation, although there was a significant increase in the treatment group after 4 weeks of exercise.

HRV is influenced by several factors including comorbidity, psychological, circadian rhythm, and physical activity of each individual (Sammito and Böckelmann, 2016). This study did not control the observation of sleep patterns, psychology, and physical activity of each individual outside the treatment. Researchers assume that those factors affect HRV recording results after 4 weeks of HIIT intervention hence there was no difference between the two groups. The value of Cohen's D effect size in the treatment group is medium (Cohen's $D=0.70)$ for SDNN, large (Cohen's D $=0.83$ ) for RMSSD, and medium (Cohen's D $=0.77$ ) for LF/HF Ratio shows that the HIIT exercise had sufficient effect to provide changes in HRV in overweight/obese men.

\section{Conclusion}

HIIT intervention for 4 weeks increases the value of RMSSD and SDNN while lowering the LF/HF ratio in overweight/obese men at the Medical Rehabilitation Unit RSUD dr. Soetomo. Furthermore, larger RCTs will be needed to increase confidence in the effects of HIIT on HRV and to determine practice guidelines. The HIIT exercise can be added as an alternative exercise program to increase cardiac parasympathetic activity in overweight/obese men. The results of this study can be used as a reference for future research.

\section{Acknowledgements}

We thank Indonesian Government through the Directorate General of Higher Education, which has provided financial assistance for this research through the PTUPT grant program. Additionally, we thank LPDP, Indonesia which has provided scholarship for the researcher.

\section{References}

Abdullah, A., Peeters, A., de Courten, M., et al. 2010. The magnitude of association between overweight and obesity and the risk of diabetes: a meta-analysis of prospective cohort studies. Diabetes Res Clin Pract. 89(3):309-319.

Abrantes, C., Sampaio, J., Reis, V., Sousa, N., and Duarte, J. 2012. Physiological responses to treadmill and cycle exercise. Int J Sports Med 33: 26-30.

Acheson, K. J., Blondel-Lubrano, A., Oguey-Araymon, S., 2011. Beaumont, M.; Emady-Azar, S, et al. Protein choices targeting thermogenesis and metabolism. Am. J. Clin. Nutr. 93, 525-534.

ACSM. 2018. Guidelines for Exercise Testing and Prescription - Tenth Edition. China: Wolters Kluwer.

ADA. 2004. Diagnosis and Classification of Diabetes - Position Statement Diabetes Care -Volume 27. 5-10

Ahmadizad, S., Avansar, A.S., Ebrahim, K., Avandi, M. and Ghasemikaram, M., 2015. The effects of short-term high-intensity interval training vs. moderate-intensity continuous training on plasma levels of nesfatin-1 and inflammatory markers. Hormone molecular biology and clinical investigation, 21(3), pp.165-173.

Ahmed, A.S., Ahmed, M.S., Mahmoud, W.S., Abdelbasset, W.K. and Elnaggar, R.K., 2019. Effect of high intensity interval training on heart rate variability and aerobic capacity in obese adults with type 2 diabetes mellitus. Bioscience Research. 16 (3), pp.2450-2458.

Alberti and Zimmet. (1998). Definition, Diagnosis and Classification of Diabetes Mellitus and its Complications. Diabetic Medicine, 539-553.

Alberti, G. (2010). The Classification and Diagnosis of Diabetes Mellitus. Textbook of Diabetes Fourth Edition. Oxford: Blackwell Publishing Ltd.

Annaswamy, T., Houtrow, A., Saxena, D., \& Yang, W. 2016. Quality and outcome for medical rehabilitation. Dalam D.X. Cifu, Braddom's Physical Medicine \& Rehabilitation 5th Edition. Philadelphia: Elsevier.

Bilous, R., \& Donelly, R. 2010. Chapter 11- Management of type 2 diabetes. In Handbook of Diabetes, 4th edition (p. 79). Oxford: Blackwell Publisihg Ltd.

Boor, P., Celec, P., Beuliak, M., Grancic, P., \& al., e. 2009. Regular moderate exercise reduces advanced glycation and ameliorates early diabetic nephropathy in obese Zucker rats. Science Direct , 1669-1677.

Boyer, J., \& Earp, J. 1997. The development of an instrument for assessing the quality of life of people with diabetes. Diabetes39. Med Care , 440-53. 
Caballero, B. 2007. "World Health Organisation. Controlling the global obesity epidemic". Johns Hopkins Bloomberg School of Public Health. vol 29:1-5

Cai, H., Li, G., Zhang, P., Xu, D., \& Chen, L. 2016. Effect exercise on the qulity of life in type 2 diabetes mellitus: a systematic review. Quality of Life Res .

Candido, R., Cooper, M., \& Jandeleit-Dahm, K.. 2010. The Pathogenesis of Macrovascular Complications Atherosclerosis in Diabetes. Oxford: Wiley-Blackwell.

Carmienke S, Freitag MH, Pischon T et al. 2013. General and abdominal obesity parameters and their combination in relation to mortality: a systematic review and meta-regression analysis. Eur J Clin Nutr. 67(6):573-585

Cassidy, S., Thoma, C., Houghton, D. 2016. High-Intensity Interval Training: a Review of Its Impact on Glucose Control and Cardiometabolic Health. Diabetologia. Vol. 16. 1-17

Chandrashekara, S., 2014. C-reactive protein: An inflammatory marker with specific role in physiology, pathology, and diagnosis. Internet Journal of Rheumatology and Clinical Immunology, 2(S1).

Chia-Lin, L., Hsu-Min, T., Rou-Fang, T., \& Shwn-Jee, L. 2006. The Effectiveness of an aerobic exercise intervention on worksite health-related physical fitness - A Case in High-Tech Company. Chang Gung Med J, 100-106.

Ciolac, E.G., Bocchi, E.A., Bortolotto, L.A., Carvalho, V.O., Greve, J.M. and Guimaraes, G.V., 2010. Effects of high-intensity aerobic interval training vs. moderate exercise on hemodynamic, metabolic and neuro-humoral abnormalities of young normotensive women at high familial risk for hypertension. Hypertension Research, 33(8), pp.836-843.

Clark, M., Sterret, J., \& Carson, D. 2000. Diabetes guidelines: a summary and comparison of the recommendations of the American diabetes Association, Veterans Health Administration, and American Association of Clinical Endocrinologists. Clin Ther, 899-910.

Cochran, J., \& Conn, V. 2008. Meta-analysis of quality of life outcomes following diabetes self-management training. Diabetes Educ. , 815 .

Coldberg, S., Sigal, R., \& Barry, B. 2010. Exercise and Type 2 Diabetes. AD: Joint Position Statement. Virginia: American Diabetes Association.

Costa, J., Moreira, A., Moreira, P., Delgado, L. and Silva, D., 2019. Effects of weight changes in the autonomic nervous system: a systematic review and meta-analysis. Clinical Nutrition, 38(1), pp.110-126.

DeFronzo, R. 2009. From the Triumvirate to the Ominous Octet: A New Paradigm for the Treatment of Type 2 Diabetes Mellitus. Diabetes, 773-795.

ESPRM. 2006. White book on physical and rehabilitation medicine in europe. Europe: Section of Physical and Rehabilitation Medicine and European Board of Physical and Rehabilitation Medicine.

Fal, A., Jankowska, B., Uchmanowicz, I., Sen, M., Panaszek, B., \& Polanski, J. 2010. Type 2 diabetes quality of life patients treated with insulin and oral hypoglycemic medication. Acta diabetol , 237-242.

Farah, B.Q., Barros, M.V., Balagopal, B. and Ritti-Dias, R.M., 2014. Heart rate variability and cardiovascular risk factors in adolescent boys. The Journal of pediatrics, 165(5), pp.945-950.

Flegal, K. M., Kit, B. K., Orpana, H. et al. 2013. Association of all-cause mortality with overweight and obesity using standard Index Massa Tubuh categories: a systematic review and meta-analysis. JAMA. 309(1):71-82

Galgani, J., Ravussin, E. 2008. Energy metabolism, fuel selection and body weight regulation. Int. J. Obes. 32, S109-S119.

Giacco, F., \& Brownlee, M. 2010. Pathogenesis of Micovascular Complications. In R. Holt, C. Cockram, A. Flyvbjerg, \& B. Goldstein, Textbook of Diabetes - Fourth Edition (p. 556). Oxford: Wiley-Blackwell.

Gibala, M., Little, J. Macdonald, M., Hawley J. 2012. Physiological adaptations to low-volume, high-intensity interval training in health and disease. J Physiol. 1077-1084

Guh, D.P., Zhang, W., Bansback, N., et al. 2009. The incidence of co-morbidities related to obesity and overweight: a systematic review and meta-analysis. BMC Public Health 9:88

Hafstad, A., Boardman, N., \& Aasum, E. 2015. How Exercise May Amend Metabolic Disturbances in Diabetic Cardiomyopathy. Antioxidants \& Redox Signaling, pp: 1587-1605.

Hayyan, A., Maria, P., \& Idha, N. 2017. Adoption Evaluation of Indonesia Language Short Form 36 Cross Cultural Adaptation on People With Musculoskeletal Pain. International Meeting on Regenerative Medicine .

Hex, N., Bartlett, C., Wright, D., Taylor, M., \& Varley, D. 2012. Estimating the current and future costs of Type 1 and Type 2 diabetes in UK, including direct health costs and indirect societal and productivity costs. Diabetic Medicine, 855862.

Heydari, M., Freund, J., Boutcher, S. H. 2012. The Effect of High-Intensity Intermittent Exercise on Body Composition of Overweight Young Males. Journal of Obesity.1-8

Holt, R., Cockram, C., Flyvbjerg, A., \& Goldstein, B. 2010. Textbook of Diabetes - 4th edition. Oxford: Wiley-Blackwell.

Ito. S. 2019. High-Intensity Interval Training For Health Benefits and Care of Cardiac Diseases- The Key To an Efficient Exercise Protocol. World Journal of Cardiology. Vol. 11. Pp: 171-188

Ivy, J. 1997. Role exercise training in the prevention and treatment of insulin resistance and non insulin dependent diabetes mellitus. Sports Medicine - Ed. 24, pp: 321-336.

Johnston, M., Layte, R., Graham, K., Findley, P., \& Hansen, A. 2010. Systematically Assessing and Improving the Quality and Outcomes of Medical Rehabilitation Programs. Dalam W. Frontera dan J. DeElisa, DeLisa's Physical Medicine \& Rehabilitation: Principles \& Practise 5th Edition. Philadelphia: Lippincott Williams dan Wilkins.

Kaplan, R. 2002. Quality of Life: An Outcomes Perspective. Arch Phys Med Rehabil Vol 83, Suppl 2, Dec, S44-S50.

Karstoft, K., Winding, K., Knudsen, S. 2012. The effects of free-living interval-walking training on glycemic control, body Composition, and physical fitness in tipe 2 diabetic patients: a randomized, controlled trial. Diabetes Care. Vol:36. 228-236.

Kementerian Kesehatan Republik Indonesia. Hasil Utama Riskesdas 2018. [internet] 2019 [dikunjungi 29 Oktober 2019]. tersedia dari: depkes.go.id/resources/download/info-terkini/materi_rakorpop_2018/Hasil\%20Riskesdas\%202018.pdf 
Kilpatrick, M. Little, J., \& Jung M, E. 2014. High-Intensity Interval Training: A Review of Physiological and Psychological Responses. ACSM's Health and Fitness Journal. Vol 5. 10-6

Kisan, R., Kisan, S., Anitha, O., \& Chandrakala, S. 2012. Treadmill and bicycle ergometer exercise: cardiovascular response comparison. . Global Journal of Medical Research, Ed. 12 , pp: 5.

Krein, S., Heisler, M., Piette, J., Makki, F., \& Kerr, E. 2005. The effect of chronic pain on diabetes patientes' self-management. Diabetes Care - Ed. 28 , pp: 65-70.

Laborde, S., Mosley, E. and Thayer, J.F., 2017. Heart rate variability and cardiac vagal tone in psychophysiological researchrecommendations for experiment planning, data analysis, and data reporting. Frontiers in psychology, 8, p.213.

Lemos, T. 2011. Regular physical exercise training assists in preventing type 2 diabetes development: focus on its antioxidant and anti-inflmatory properties. Cardiovasc Diabetol.

Löllgen, H., Böckenhoff, A. and Knapp, G., 2009. Physical activity and all-cause mortality: an updated meta-analysis with different intensity categories. International journal of sports medicine, 30(03), pp.213-224.

Liu, Y.Z., Wang, Y.X. and Jiang, C.L., 2017. Inflammation: the common pathway of stress-related diseases. Frontiers in human neuroscience, 11, p.316.

Manore, M.M. 2015. Rethinking energy balance: Facts you need to know about weight loss and management. ACSM's Health Fit. J. 19, 9-15.

Manore, M.M. 2015. Weight management for athletes and active individuals: A brief review. Sports Med. 45, 83-92.

Manore, M.M., Meyer, N.L., Thompson, J. 2009. Sport Nutrition for Health and Performance, 2nd ed.; Human Kinetics: Champaign, IL, USA. 25-108.

Martin, C., Church, T., Thompson, A., Earnest, C., \& Blair, S. 2009. Exercise dose and quality of life: a randomized controlled trial. Arch Intern Med, 269-278.

Masthoff, E., Trompenaars, F., Heck, G., Hodiamont, P., \& De Vries, J. 2006. Quality of life and psychopathology: investigations into their relationship. Australian and New Zealand Journal of Psychiatry, 333-340.

McArdle, W., Katch, F., \& Katch, V. 2005. Essentials of Exercise Physiology 3rd ed. Philadelpha: Lippincott, Williams and Wilkins.

McCrae, G., Payne, A., Zelt, J. 2012. Extremely low volume, whole-body aerobic resistance training improves aerobic fitness and muscular endurance in females. J Appl Physiol Nutr Metab. Vol. 37. 1124-1131

Morici, G., Gruttad'Auria, C., Baiamonte, P., Mazuuca, E., Castrogiovanni, A., \& Bonsignore, M. 2016. Endurance training: is it bad for you? Breathe, 140-147.

Myers, V., McVay, M., Brashear, M., Johannsen, N., Swift, D., Kramer, K., et al. 2013. Exercise Training and Quality of Life in Individuals with Type 2 Diabetes. Clinical Care Research , 1884-1890.

Nicolucci, A., \& Balducci, S. C. 2012. Italian Diabetes Exercise Study Investigators. Relationship of exercise volume to improvements of quality of life with supervised exercise trainin in patients with type 2 diabetes in a randomised controlled trial: the Italian Diabetes and Exercise Study. Diabetologia , 579-588.

Ouerghi, N., Fradj, M. K. B., Bezrati, I., Khammasi, M., Feki, M., Kaabachi, N., et al. 2017. Effects of high-intensity interval training on body composition, aerobic and anaerobic performance and plasma lipids in overweight/obese and normalweight young men. Biology of Sport.34:384-392

Perhimpunan Dokter Spesialis Kardiovaskular Indonesia. 2013. Pedoman Tatalaksana Dislipidemia Edisi Ke-1. Jurnal Kardiologi Indonesia. 24-25

PERKENI. 2015. Konsensus Pengelolaan dan Pencegahan Diabetes Melitus Tipe 2 di Indonesia. Jakarta: PB. PERKENI.

Picard, M., Tauveron, I., Magdasy, S., Benichou, T., Bagheri, R., Ugbolue, U.C., Navel, V. and Dutheil, F., 2021. Effect of exercise training on heart rate variability in type 2 diabetes mellitus patients: A systematic review and metaanalysis. PloS one, 16(5), p.e0251863.

Porszasz, J., Casaburi, R., Somfay, A., \& Woodhouse, L. a. 2003. A Treadmill Ramp Protokol Using Simultaneous Changes in Speed and grade. Medicine and Science in Sports and Exercise.

Reid, R., Tulloch, H., \& Sigal, R. 2010. Effects of aerobic exercise, resistance exercise or both, on patient-reported health status and well-being in type 2 diabetes mellitus: a randomised trial. Diabetologia , 632-640.

Riebe, D., Ehrman, J., Ligouri, G., \& Magal. 2018. ACSM's Guidelines for Exercise Testing and Prescription. Tenth Edition. Philadephia: Wolters Kluwer.

Rodrigues, J.A.L., Yamane, A.C., Gonçalves, T.C.P., Kalva-Filho, C., Papoti, M. and Júnior, C.R.B., 2019. Fed and fasted states on heart rate variability, hemodynamic heart rate and blood pressure in adults submitted to moderate aerobic exercise. IJC Heart \& Vasculature, 23, p.100378.

Rosenbaum, P. 2010. The randomized controlled trial: An excelent design, but can it address the big questions in neurodisability? . Developmental Medicine and Child Neurology - Ed. $52,111$.

Shaffer, F. and Ginsberg, J.P., 2017. An overview of heart rate variability metrics and norms. Frontiers in public health, p.258.

Sigal, R. J., Kenny, G. P., Wasserman, D. H., \& Castaneda-Sceppa, C. 2004. Physical Activity/Exercise and Type 2 Diabetes. Diabetes Care, Volume 27, Number 10 , 2518-2539.

Singh, N., Moneghetti, K.J., Christle, J.W., Hadley, D., Froelicher, V. and Plews, D., 2018. Heart rate variability: an old metric with new meaning in the era of using mhealth technologies for health and exercise training guidance. part two: prognosis and training. Arrhythmia \& electrophysiology review, 7(4), p.247.

Smeltzer, \& Bare. 2001. Keperawatan Medical Bedah Brunner dan Suddart Edisi 8. Jakarta: EGC.

Speer, K.E., Semple, S., Naumovski, N. and McKune, A.J., 2020. Measuring heart rate variability using commercially available devices in healthy children: A validity and reliability study. European Journal of Investigation in Health, Psychology and Education, 10(1), pp.390-404.

Speiser, P.W., Rudolf, M. C. J., Anhalt, H., Comacho-Hubner, C., Chiarelli, F., Elakim, A, et al. 2005. Childhood obesity. Journal of Clinical Endocrinology \& Metabolism. 90:1871-1887.

Spilker, B. 1990. Introduction. In: Spilker B, ed. Quality of life assessmens in clinical trials. New York: Raven Press , 3-9. 
Taylor JL, Holland DJ, Spathis JG. 2019. Guidelines for the Delivery and Monitoring of High Intensity Interval Training in Clinical Populations, Progress in Cardiovascular Diseases.

Tarquini, R., Lazzeri, C., Rotella, \& Gensini, G. 2010. The Diabetic Cardiomyopatyh. Acta Diabetol .

Tolfrey, K., Smallcombe, J. 2017. Oxford Textbook of Children's Sport and Exercise Medicine, 3rd ed. Oxford. Oxford University Press. 477-91

Trief, P., Wade, M., Pine, D., \& Weinstock, R. 2003. A comparison of health-related quality of life of elderl and youber insulin-treated adults with diabetes. Age and Ageing vol. 32 , pp613-618.

Trikklalinou, A., Papazafiropoulou, A., \& Melidonis, A. 2017. Type 2 Diabetes and Quality of Life. World Journal of Diabetes , 120-129.

Tulaar, A., Wahyuni, L., Wirawan, R., \& Aliwarga, J. 2013. Terapi Latihan: Latihan Kebugaran Fisik. In: Layanan Kedokteran Fisik dan Rehabilitasi. Jakarta: PT Adhitama Multi Kresindo.

Wang, H.M. and Huang, S.C., 2012. SDNN/RMSSD as a surrogate for LF/HF: a revised investigation. Modelling and Simulation in Engineering, 2012.

Ware, J., \& Snow, K. 1993. SF-36 Health Survey Manual and Interpretation Guide. The Health Institue, New England Medical Center .

World Cancer Research Fund/American Institute for Cancer Research. 2007. Food, Nutrition, Physical Activity, and the Prevention of Cancer: a Global Perspective. AICR, Washington DC

World Health Organization. 2000.Obesity: preventing and managing the global epidemic. World Health Organization. Technical Report Series 894, Geneva

WHO. 2011. Concept Paper WHO Guidelines on Health-Related Rehabilitation (Rehabilitation Guidelines). 1-5.

World Health Organization. 2013. Global action plan for the prevention and control of NCDs 2013-2020. World Health Organization, Geneva

World Health Organization. 2016. Obesity and overweight. WHO https://www.who.int/mediacentre/factsheets/ fs311/en/ (2016).

Yadav, R.L., Yadav, P.K., Yadav, L.K., Agrawal, K., Sah, S.K. and Islam, M.N., 2017. Association between obesity and heart rate variability indices: an intuition toward cardiac autonomic alteration-a risk of CVD. Diabetes, metabolic syndrome and obesity: targets and therapy, 10, p.57.

Yadav, A.. 2018. A study to evaluate cardiovascular responses by using treadmill and ergometer bicycle exercise in young adults. Indian Journal of Health Sciences and Biomedical Research (KLEU , pp: 81.

Yanovski, J. A. 2018. Obesity: Trends in underweight and obesity - scale of the problem. Nat. Rev. Endocrinol. 14, 5-6. 12

Zulian, L., Santos, M., Veras, V., Rodrigues, F., Arrelias, C., \& Zanetti, M. 2013. Quality of life in patients with diabetes using the diabetes 39 (D-39) Instrument. Rev Gaucha Enferm, 138-146. 